\title{
DEVELOPING A MAP USE MODEL FOR WEB MAPPING AND GIS
}

\author{
Bert Veenendaal
}

Department of Spatial Sciences, Curtin University, GPO Box U1987, Perth, Australia - b.veenendaal@curtin.edu.au

\author{
Commission IV, WG IV/5
}

KEY WORDS: Web mapping, Web GIS, Map use model, Geoweb, Intelligence, Web mapping and services

\begin{abstract}
:
Web mapping and GIS technology and applications are developing rapidly in response to growing user and application demands. Technologies over the past decade, including digital globes, positioning-enabled mobile devices and cloud-based geoweb services, have been instrumental in fostering this growth. However, not only technology, but the dissemination and access to geoweb information and services by users and applications have been and are continuing to be important drivers of growth and expansion. The access and use of geospatial information and services is widespread and worldwide, and its use is driving the need to further develop and expand geospatial web information and services.
\end{abstract}

This paper considers a model for web mapping use that is based on the original map use cube by MacEachren \& Kraak (1997). The model incorporates technology, usability and knowledge that must be considered for the development and future of geospatial web mapping and services. Such a model assists in the design and development of intelligent web mapping and GIS, and informs the research directions being taken in this fast evolving discipline.

\section{INTRODUCTION}

\subsection{General Overview}

With the rapid development of web mapping and online geographic information systems (GIS) technology comes the challenge of ensuring the use of web maps. As the usage of online web maps and services by an ever-increasing user base continues to expand, how do we ensure that these maps remain useful and useable?

The map use cube was identified by MacEachren \& Kraak (1997) to address the need for maps to be used as a means of visualisation to support and facilitate thinking and problem solving. This map use model was developed at a time when online maps were still very static and primitive, the audience was very limited to those in the scientific world and the purpose was to stimulate visual scientific thinking. In the past two decades there have been quite a number of developments which have impacted on all aspects of map use.

\subsection{Aim and scope}

This paper reviews the map use cube of MacEachren \& Kraak which involves a number of factors that influence map use towards a particular map goal. A number of map developments using web technology are then outlined. These developments have somewhat dated the map use cube, and the paper proposes how it can be enhanced into a web map use cube model. The conclusion is that more intelligence is needed in building maps that promote map use by target users.

This paper does not test and evaluate the web map use cube in relation to each of the three factors that influence web map use. What it does do is stimulate further thinking about online map use and how increased intelligence is necessary to build maps that can effectively communicate, which of course is the purpose of a map.

\section{BACKGROUND AND DEVELOPMENTS}

\subsection{Map use cube}

The map use cube (MacEachren \& Kraak, 1997; Van Elzakker, 2004) identifies four map use goals within three axes, namely, the audience ranging from private to public, the data relations ranging from unknown to known and the level of interaction ranging from low to high (Figure 1). The goal of presenting a map occurs primarily for a public audience with low interaction among data and information that is relatively well known. On the other hand, where specific persons are dealing with unknown information, their goal may be to explore for patterns using high interactivity in the visualisation of the map. The goals of synthesising and analysing information lie somewhere between these two extremes.

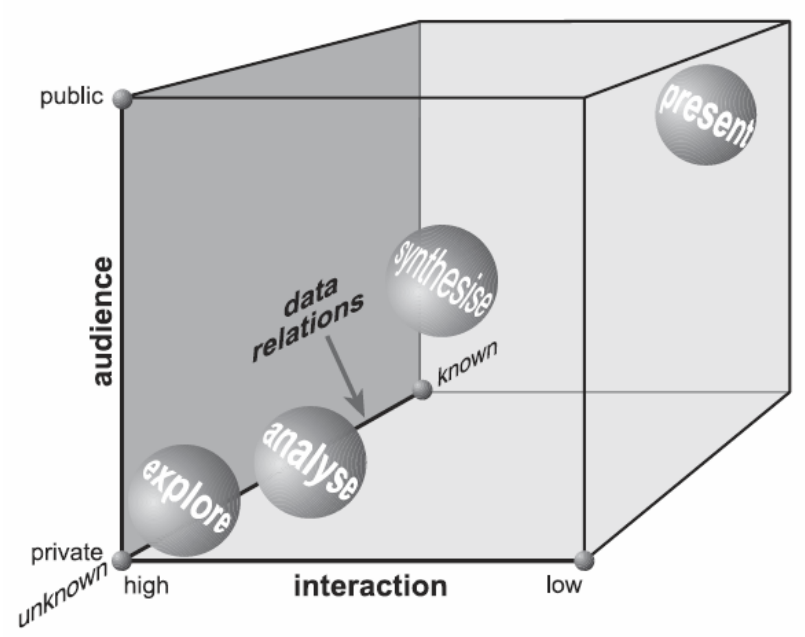

Figure 1: Map use cube and goals of map use (MacEachren \& Kraak, 1997) 
This map use cube was developed in a time when web maps were not prevalent and most maps were rather static with some potential to manipulate the display and visualisation parameters. Further, the wider audience being the general public, would only view pre-defined maps with well-labelled information and would have little or no opportunity to interact with the map itself, at least not in the way of changing viewing parameters or preferences (refer to top right of Figure 1). It was a very small audience that had sufficient geospatial skills and tools that could manipulate the map and its visual display to draw out particular map features or identify patterns or previously hidden information (refer to bottom left of Figure 1). This small audience tended to comprise highly skilled cartographers, geographic information systems (GIS) scientists and spatial analysts.

\subsection{Web related developments in mapping}

A number of developments have occurred over the past couple of decades that have significantly impacted on maps and map use. These include the growth of maps on the web, the interactive Web 2.0 technologies and the development of virtual globes to a global community (Figure 2).

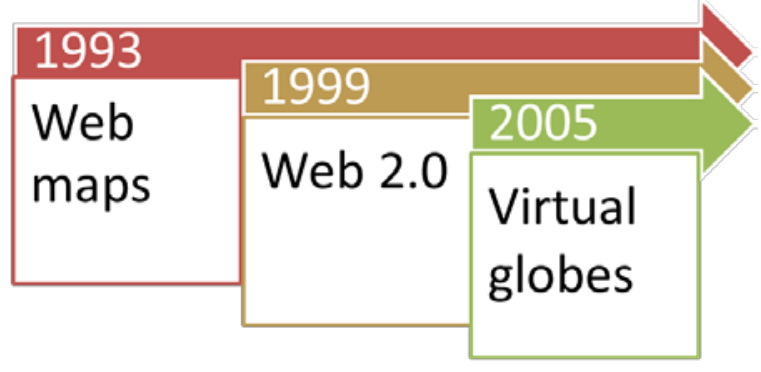

Figure 2: Map developments on the web

The first of these is the advent of maps on the web. Going beyond simply image maps embedded in a web page, the first web maps, and the many online map atlases constructed thereafter, were little more than relatively static paper maps. For example, the first web map was the Xerox PARC Map Viewer accessed using a small range of options which were implemented via hyperlinks (Putz, 1993).

However, web maps have developed rapidly to become dynamic and very interactive, with underlying AJAX technology that allows them to be updated, customised and manipulated according to a range of system and user parameters (Fu \& Sun, 2010; Peterson, 2014). Additionally, these maps have developed with a broad range of functionality, to the point that many are web GIS systems that alter and generate underlying datasets. For example, Esri's ArcGIS Online (Esri, 2015a) can integrate data from a range of online sources and services and manipulate them through GIS functions that perform spatial analysis, generate new datasets and visualise spatial information and patterns.

Web map services and cloud based services provide geospatial data and functionality which can be accessed directly by a user, but also indirectly by a web map. So essentially, based on user interaction, web maps can be modified and customised with additional information accessed via background web services, in order to better communicate and meet the users' needs.
A further development has been the shift towards Web 2.0 marking the ability to interact with the web in a dynamic and participatory manner. Instead of the web being simply a repository of information, including maps, it now allows users to interact and provide data to engage with others in an online environment (DiNucci, 1999; O’Reilly, 2005). Further, the growth of mobile and satellite positioning technologies means that users can access specific locations and incorporate such position information into online data repositories and services.

The web has become a shared and collaborative platform with user-generated content utilised within a rich interactive user experience ( $\mathrm{Li}$ et. al., 2011). Examples of such Web 2.0 developments in addition to mobile positioning include interactive maps and virtual globes, blogs, mashups, wikis and social networking. Such a rich user online dialog has paved the way for web based maps to be highly interactive, enhanced with user content, and harnessing collective knowledge and intelligence (Veenendaal \& West, 2011).

A third development that has had a major impact on maps and map use is the release of virtual globes commencing with Google Earth in 2005 (Google, 2005). Firstly, the interface with the virtual globe provides users with an immersive 3D experience which is intuitive and relatively easy for users to navigate through imagery and other data layers (Songer, 2012). Secondly, the user population exposed to maps grew explosively from a small number of professionals who were trained to use mapping software such as GIS to billions of users worldwide who could access maps via the internet. The combination of broadening the map user base and providing easy of map use to this global user base had a major influence in enhancing and promoting map use.

\section{WEB MAP USE MODEL}

\subsection{Enhancing the map use cube}

The map use cube has provided an excellent framework for understanding and analysing map use over the past two decades. However, with the further developments regarding the use of maps on the web, it could be enhanced to consider the newer developments and changed context of map use.

Hence, the development of a web map use model is not the creation of a new model, but an enhancement of the map use cube that considers the context of web maps and the related developments over the past two decades.

One effect of the web mapping developments is that a greater number and diversity of users accesses online maps. Hence, to ensure that these maps are useful, they need to cater for and communicate to a more diverse audience. The users of the web are users of web maps, and they now include almost every person on the earth, and not only geospatially-literate or technological-savvy people.

Because of the enormous advances in interactivity with the web, marked especially by Web 2.0 and virtual globe developments, the potential for web maps to incorporate a broad range of functionality means that users could do much more with them. Hence a map use framework must take into account the increased range of functionality that is possible, even to the extent of web GIS providing true spatial analytical 
functionality. This goes much beyond the "interaction" with maps that was available when the map use cube was designed.

Finally, the ability to discover, retrieve, manipulate and recreate data using online functionality, web services and cloudbased platforms provides a means to integrate and process data and information online and without the user requiring access to specialist tools. Hence, in a map use scenario, data and information processed from many sources and services in the cloud can be used to construct a map. Hence, the information presented or manipulated in a web map can be customised or tailored to suit the needs of the target users. This manipulation of geospatial data goes well beyond the known and unknown data relations specified for the map use cube.

\subsection{Web map use cube}

The web map use cube is a model that modifies and enhances the original map use cube, taking into account the web developments that have occurred in mapping. The web map use cube model is presented in Figure 3. The three axes are similar in concept to those for the map use cube, namely, being focussed on audience, data and interaction, but have been enhanced or redefined to address the use of web maps.

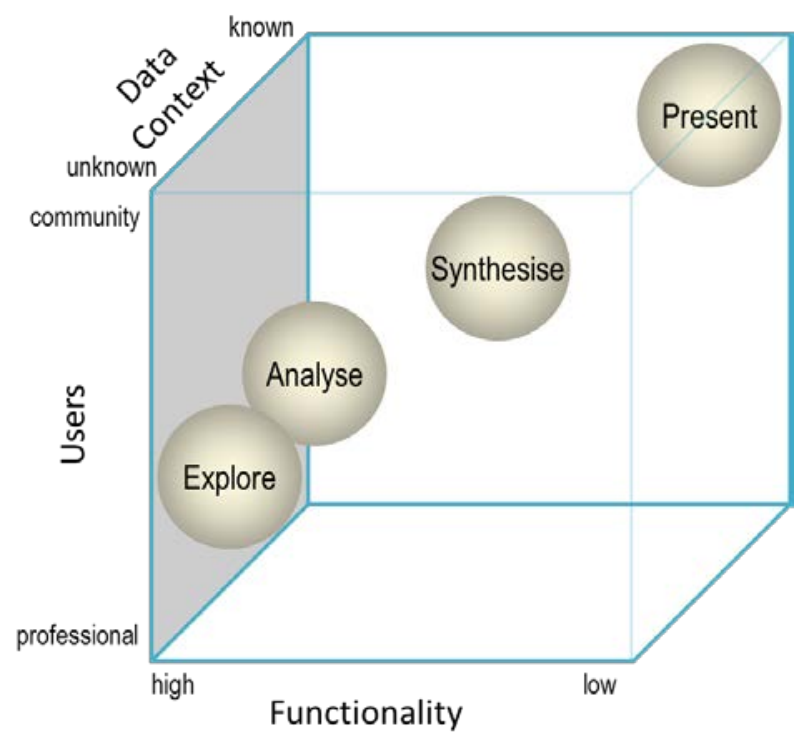

Figure 3: Web map use cube (Adapted from MacEachren \& Kraak, 1997)

The users axis takes into account the expanded and diverse range of users that have access to and use online maps. Potentially this is the entire global community because of its access to the internet. These users may not be geospatially literate but have some spatial awareness via online tools such as virtual earth and various maps encountered along the journey of online navigation and browsing. On the other hand, users can be professionals who are geospatial experts or cartographers who understand maps and can manipulate geospatial information using a range of specialised tools for that purpose. The implications are that maps must address a very broad range of uses by users that vary considerably in their capacity to read, understand and manipulate maps online.

What was termed interaction in the map use cube has broadened with the term functionality. The interaction referred to includes the ability to manipulate the map view or select options to influence the choice of data or display. However, even a basic web map has the ability for users to pan, zoom and navigate through the map display for, in essence, a relatively high degree of interaction even though the functionality might still be low. High functionality extends to being able to manipulate the data using GIS functions that can interact with a multi-view, multi-dimensional map in space and time. Hence web maps can range from basic interactive maps for viewing and browsing to web GIS functionality for spatio-temporal analysis and modelling. Hence the term functionality captures more than simply interaction.

The third dimension of the web map cube is related to the data context. In the map use cube, this dimension referred to the data relationships and presenting what was known or revealing what is unknown about the data and relationships. In fact, the use of the data very much depends on the context of that data, whether known, or in the process of trying to reveal the unknowns. The context, although it involves data relationships, includes a much broader context such as historical, geographical, temporal, etc. Where this context is well known, the map can be customised by that context to meet the needs of the target user and requested functionality. Where the data context is largely unknown, the user may require different functionality to reveal a currently unknown context. Hence in a web map use model, the data context spans a wide range of contextual parameters which define how a web map will be visualised, manipulated and viewed. This data context can then, in turn, lead to the web map being tailored with the functionality and data required by the particular target users.

\subsection{Map use purposes}

For the purposes of map use as defined by MacEachren \& Kraak 1997, they are arranged in the web map cube in a similar fashion as for the map use cube (Figure 3). Although similar, the placement for especially the higher order purposes has been shifted in the cube towards community users.

The typical goal of using a map to present information will involve the community with a low but reasonable amount of navigational functionality to manipulate the map for viewing in a known data context. On the other hand, in an environment with an unknown data context, professional users can take advantage of exploratory and analytical geospatial functionality to reveal and discover patterns and information via the dynamic web map visualisation.

A distinction from the map use cube is that the Explore map goal has been targeted not only for professional GIS users but also for a broader range of users that are spatially literate and are able to access the online GIS functionality without necessarily being a GIS expert. Such tools when appropriately applied in a data context and also contexualised for the target user can be relatively easy to utilise in an online web map environment. For example, the Story Maps Gallery provides a range of "stories" using ArcGIS Online developed by users across industries including tourism, disaster management, parks and recreation, history, science and technology, etc. (Esri, 2015b).

\section{SUMMARY AND CONCLUSIONS}

Considering the developments and progression in technology with regards to maps and map use, it is appropriate to also 
enhance the models for measuring and evaluating the use of maps. This paper discusses enhancements to the original map use cube developed by MacEachren and Kraak (1997) that form the basis for a web map use cube model.

The web map use cube considers the broadened and diverse user base globally that accesses web maps in some form or another, thanks to the expansion of online maps and virtual globes. These users are offered a range of functionality for manipulating the map according the purpose of the map. They do this in the context of the data, which if known, informs the map view. Otherwise, they utilise higher level geospatial functionality to manipulate and visualise the map to explore and reveal what is unknown. Hence, the data context is important to visualise the map in such a way as to effectively communicate its message to the target user.

Being able to construct a map that is effective in communication is an ongoing challenge. With the continued growth in web mapping and web services technologies, there is an increasing need to automate the contextualisation that needs to occur as a web map is constructed and manipulated. Further research is needed to identify the intelligent contextual environment, not only for the data, but also for users and the functionality required. As web mapping technology becomes smarter, so too do web maps need to communicate much more intelligently - linking users, functionality and data to impart knowledge and wisdom.

\section{REFERENCES}

DiNucci, D. Fragmented future. Print 1999, 32, 221.

Esri. 2015a. ArcGIS Online. Esri, Redlands, California, https://www.arcgis.com/home, (4 May 2015).

Esri. 2015b. Story Maps: Everyone has a story to tell. Esri, Redlands, California, http://storymaps.arcgis.com/en/ (4 May 2015).

Fu, P. \& J. Sun. 2010. Web GIS: Principles and applications, ESRI Press, Redlands, California.

Google. 2005. Google Launches Free 3D Mapping and Search Product. Google Inc., http://googlepress.blogspot.com.au/2005/06/google-launchesfree-3d-mapping-and_28.html (25 May 2015).

Li, S, B Veenendaal \& S Dragićević. 2011. Advances, challenges and future directions in web-based GIS mapping services. In Li, S, Dragićević, S and Veenendaal B (2011) Advances in Web-based GIS, Mapping Services and Applications, Taylor \& Francis Group, London, ISBN 978-0415-80483-7.

MacEachren A.M., M.-J. Kraak. 1997. Exploratory cartographic visualization: advancing the agenda. Computers and Geosciences, 23 (4), pp. 335-343.

O’Reilly, T. 2005. What Is Web 2.0: Design patterns and business models for the next generation of software. O'Reilly Media, http://oreilly.com/web2/archive/what-is-web-20 (25 May 2015).

Peterson, Michael P. 2014. Mapping in the cloud. The Guilford Press, New York.

Putz, S. 1993. World Map Viewer. HTTP Service at Xerox PARC, example showing default world map view at http://web.archive.org/web/20110628201303/http://www2.parc. com/istl/projects/www94/mapviewer-example1.html (5 May 2015).

Songer, Lynn. 2012. Using web-based GIS and virtual globes in undergraduate education. In Unwin et. al., 2012).

Unwin, David J., Kenneth E. Foote, Nicholas J. Tate and David DiBiase. 2012. Teaching Geographic Information Science and Technology in Higher Education. Wiley-Blackwell, John Wiley \& Sons, Ltd, Chichester, UK, ISBN: 978-0-470-74856-5.

Van Elzakker, C.P.J.M. 2004. The use of maps in the exploration of geographic data. Utrecht, University of Utrecht, 2004. ITC Dissertation 116, Utrechtse Geografische Studies 326, ISBN: 90-6809-365-7, https://www.itc.nl/library/Papers_2004/phd/vanelzakker.pdf (22 May 2015).

Veenendaal, Bert \& Geoff West. 2011. Transforming location intelligence through geospatial web-based technologies. 2nd ISPRS Workshop on Pervasive Web Mapping, Geoprocessing and Services: Our Complex World, 10 August, Simon Fraser University, British Columbia, Canada.

\section{ACKNOWLEDGEMENTS}

I would like to acknowledge the many students enrolled in the Web Mapping and Geovisualisation and Mapping units over the past several years, whose work of constructing maps and geovisualisations as part of their assessments provided me with the insight and ideas behind the web map use cube. They contributed to this unknowingly and I thank them for it. I would also like to acknowledge the constructive and insightful feedback received from the independent reviewers that served to enhance this paper. 